\title{
BIOMECHANICAL ANALYSES OF STRESS DISTRIBUTION WITHIN THE SEATED BUTTOCK AND CUSHION
}

\author{
Pei-Hsi Chou ${ }^{1}$, You-Li Chou ${ }^{2}$, Choe-JAN Chiang ${ }^{2}$, TnNG-Sheng Lin ${ }^{2}$, Shu-Zon Lou ${ }^{3}$
}

'Department of Orthopaedic Surgery, Kaohsiung Medical University, Kaohsiung

${ }^{2}$ Institute of Biomedical Engineering, National Cheng Kung University, Tainan

${ }^{3}$ Department of Industrial Engineering and Management, Chaoyang University of Technology, Taichung, Taiwan

\begin{abstract}
$+2$
ABSTRACT

The elderly wheelchair users frequently encountered the prevalence of pressure sore, also known as decubitus, since they have to be seated in the wheelchair for daily activities. The major cause induced the formation of pressure sore was that the soft tissues were over-stressed. The purpose of this study was to provide the information about internal stresses of soft tissues and establish a simplified finite element model to simulate the behavior of the interface between human buttock and cushion. Computational stresses were verified by comparing the buttock-cushion interface pressures, which was measured with Q.A. pressure pads. The displacement of the cushion was also validated with the experimental results of buttock measuring system. Two cushion geometries, flat and contoured, were adopted in this study to explore the effects on stress distributions. The results showed that the simplified finite element model was consistent with the experimental data. Contoured cushions had better stress distribution and lower interface stress.
\end{abstract}

Biomed Eng Appl Basis Comm, 2002 (December); 13: 269-272.

\section{INTRODUCTION}

The prevalence of pressure sore, also known as decubitus, was an important issue in biomedical engineering and rehabilitation technology. Wheelchair users, including elderly or disabled persons, were frequently encountered this complication. As reported by Dinsdake [1], pressure sore was observed about 25 to 85 percent in $\mathrm{SCl}$ patients. On the other hand, the spinal cord injury (SCI) patients took $44.6 \%$ of the patients who has pressure sore [2]. Pathologically, the

Received: Oct. 30, 2002; Accepted: Nov. 29, 2002

Correspondance: You-Li Chou, Ph.D., Professor

Institute of Biomedical Engineering, National Cheng

Kung University,

No. 1 University Road, Tainan, Taiwan

E-mail: ylchou@mail.ncku.edu.tw factors, which induced the formation of decubitus, were the magnitude and the lasting time of the pressure applied on soft tissues. When the excessive forces were applied on the soft tissues, the blood vessel would be obstructed and resulted in further formation of decubitus [3][4]. Kosiak [5] suggested that the greater pressure that was applied to the soft tissue would shorten the formation time of decubitus. Therefore, a better stress distribution in the soft tissue was essential and helpful for rehabilitation, which profoundly improved the living quality of disabled patients.

Surgeons found that soft tissue started to breakdown under the surface of the skin and worked its way outward to the skin. When the patient was conscious of that the compressed region started swelling and felt hurt, the dermis layer had been damaged [6]. From previous results of experimental studies [7], only the interface pressure between soft tissue and cushion was measured. However, it is difficult to determine the de- 
formation and internal stresses of the soft tissues. Since the internal soft tissue of the buttock was the origin of the formation of the decubitus, the internal stress distribution evaluation would be benefit for the design of the cushion. Finite element analysis has the ability to explore the stress distribution in biological structures and therefore becomes a powerful technique in biomechanical investigation. The objective of this study was to investigate the stress distribution of the buttock and cushion. Flat and contoured cushion was adopted to evaluate the effect of the cushion geometry on the stress distribution of the internal soft tissue. The effect of different cushion materials was also investigated.

\section{MATERIALS AND METHODS}

\subsection{Finite Element Model}

The finite element model included the cushion and buttock. Cushions are selected as PU foam material and the dimension is $40 \mathrm{~cm} \times 40 \mathrm{~cm} \times 7.8 \mathrm{~cm}$. Based on the study of Chow and Odell [8], which demonstrated a nearly symmetrical pressure distribution without thigh contact (Fig. 1), the finite element model was constructed symmetrically to the sagital plane of the whole buttock. The typical geometry of the buttock is assumed as an adult with a $40 \mathrm{~cm}$ hip width. Figure 2 shows the 3D axisymmetric buttock and it was further simplified as two-dimensional finite element models as shown in Figure 3 and Figure 4. Flat (Fig. 3) and contoured (Fig. 4) cushion was modeled to investigate the effect of the cushion geometry. ANSYS 5.0 (ANSYS Inc., IL, USA) was selected as the solver of finite element models. Large deformation was considered because of the compressible foam cushion.

The mechanical behavior of the ischial tuberosity was assumed as isotropic and linear elasticity. Referring to the previous results [9], which depicted the averaging value from experiments, the young's modulus

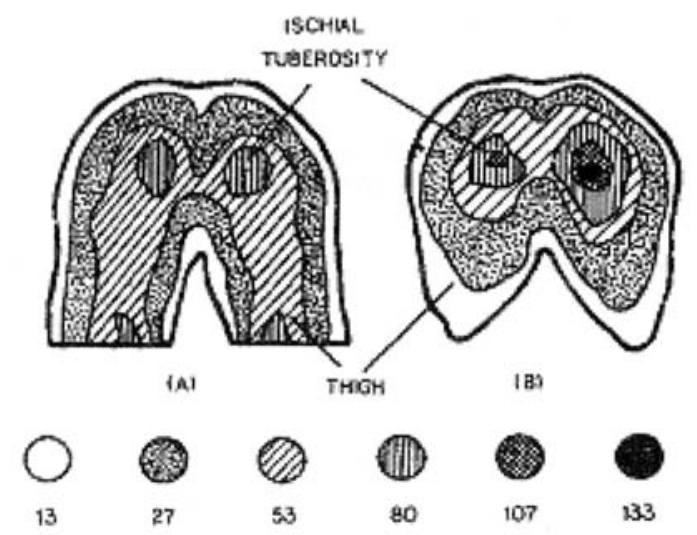

Fig. 1 Interface pressure plot for seated condition (Chow and Odell, 1978)
(E) was 17Gpa and the poisson's ratio $(v)$ was 0.31 . Generally speaking, the material properties of the biological tissue are hard to determined. Many researches have shown that the soft tissue has nonlinear, time dependent mechanical behavior. In order to simplify the analysis procedures, the material properties, such as linear elastic, homogenous and isotropic, were assigned to the soft tissue. According to the previous studies [10], the Young's modulus and Poisson's ratio of the soft tissue were $64.8 \mathrm{kPa}$ and 0.49 .

The relationship between the force and engineering strain of the cushion material was tested using the indentation approach (Fig. 5). The stress was calculated as the compressive force over the cross-sectional area of the indentation head (Formula (1)). Engineering strain was obtained from the thickness differences between the initial (25\% deformation) and compressed state (65\% deformation) of the foam (Formula (2)). Following the experiment protocol of ASTM, the 'Young's modulus of the cushion material was determined is $15 \mathrm{kPa}$. To investigate the effect of cushion material, two kinds of cushion material (Young's modulus were $15 \mathrm{kPa}$ and $20 \mathrm{kPa}$ respectively) were applied in this study.

$\sigma=F / A=F / \pi r^{2}$

F: applied force

A: the cross section area of the indentation head

$r:$ radius of the indentation head

$E=\frac{\sigma_{2}-\sigma_{1}}{\varepsilon_{2}-\varepsilon_{1}}$

$\sigma_{1}$ : stress when the cushion material deformed $25 \%$ $\sigma_{2}$ : stress when the cushion material deformed $65 \%$ $\varepsilon_{1}$ : strain when the cushion material deformed $25 \%$ $\varepsilon_{2}$ : strain when the cushion material deformed $65 \%$

Many studies have implied that most parts of the loading were carried by the skeletal structure, but it is not clear how it is transferred through the soft tissue of

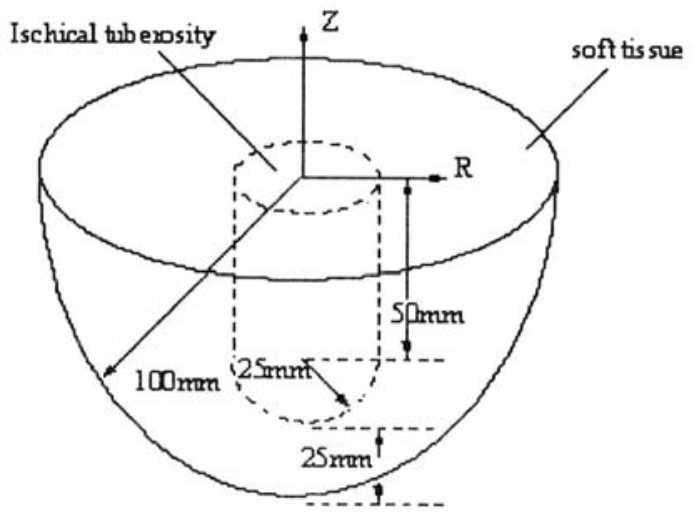

Fig. 2 Simplified hemi-buttock model 


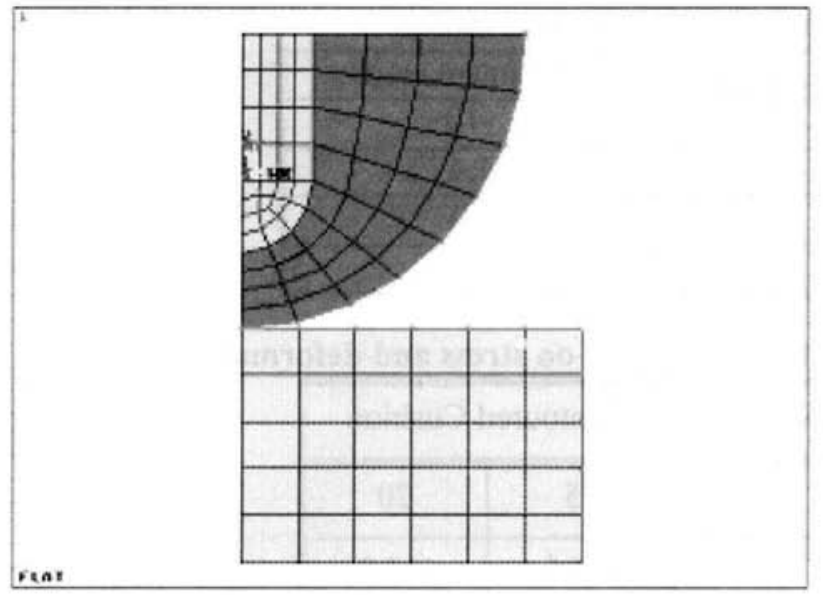

Fig. 3 Axisymmetric finite element modeling for flat cushion

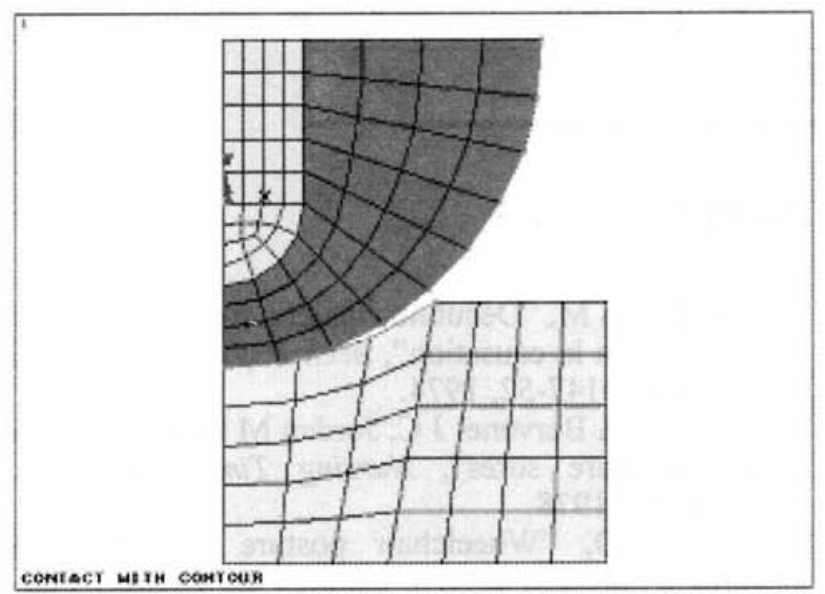

Fig. 4 Axisymmetric finite element modeling for contour cushion

the buttocks when sitting. For sitting condition with arms and feet support, a $167 \mathrm{~N}$ concentrated force, which represented that $29.2 \%$ of the total body weight (according to a preliminary test by averaging the body weights of ten normal subjects) for hemi-buttock, was applied to the center of the top surface of the ischial tuberosity. In order to simulate the cushion that was placed on a fixed rigid support, the bottom nodes of the cushion were constrained at the $\mathrm{Y}$-direction as the boundary condition. 2D node-to-surface contact elements were applied to represent the interface condition between the buttock and cushion.

\section{RESULTS}

Displacement of $y$-direction and the equivalent stress distribution of flat cushion were shown Fig.6 and 7. By comparing the $y$-direction displacement between the finite element analysis and the buttock con-

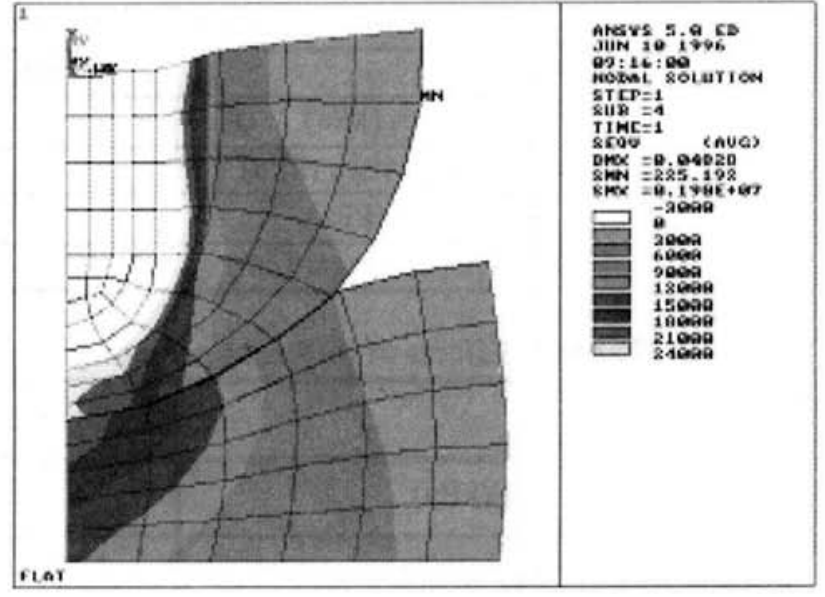

Fig. 5 Von Mises stress for the seated flat cushion

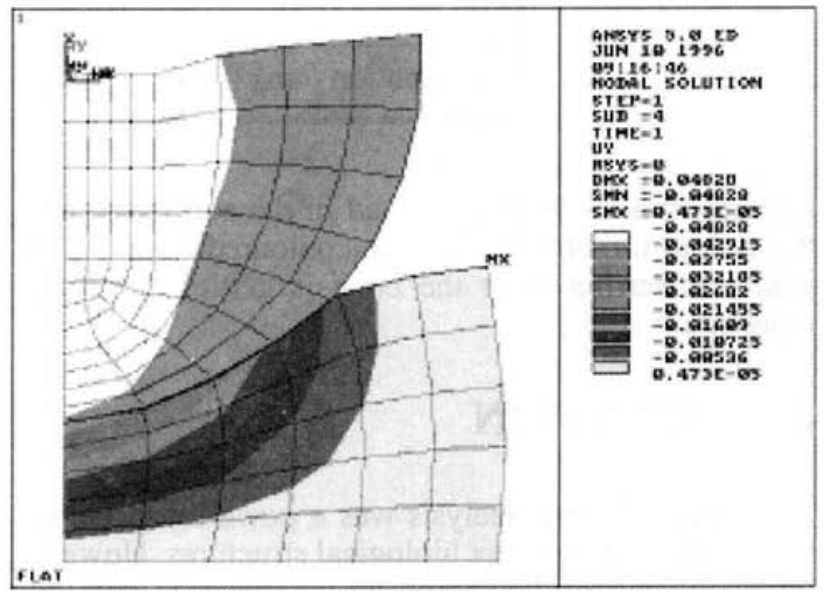

Fig. 6 Displacement of $y$-direction for the seated flat cushion

tour measuring system, the simplified finite element models used in this study were validated (Table 1). As the figure showed, the maximum displacement and peak equivalent stress were both occurred at the bottom of the ischial tuberosity. When the flat cushion was applied, the $y$-directional displacement and buttock-cushion interface pressure were $4.8 \mathrm{~cm}$ and $21 \mathrm{kPa}$ respectively.

The influences of interface pressure due to different cushion geometry and material property were evaluated. The results, as shown in Table2, have the same tendency with experimental clinical data. Contoured and softer cushion revealed the lower interface stresses because of the better pressure distribution. When seated on flat cushion, the maximum interface stress of the buttock was occurred at the lowest point of cushion geometry. However, for contoured cushion, the maximum interface stress was observed in the neighborhood of the lowest point. The contoured cushion had the higher stress and larger displacement. High 
Table 1. Results of finite element analysis and experiments

\begin{tabular}{|c|c|c|}
\hline & Finite element analysis & Experiment results \\
\hline$\sigma_{Y}(\mathrm{kPa})$ & -21 & -10 \\
\hline Von Mises $(\mathrm{kPa})$ & -21 & N.A. \\
\hline$\sigma_{1}(\mathrm{kPa})$ & -22 & N.A. \\
\hline Displacement $(\mathrm{cm})$ & 4.8 & -4.4 \\
\hline
\end{tabular}

Table 2. Effects of different geometry and material property on stress and deformation

\begin{tabular}{|l|c|c|c|c|}
\hline & \multicolumn{2}{|c|}{ Flat Cushion } & \multicolumn{2}{c|}{ Contoured Cushion } \\
\hline $\mathrm{E}(\mathrm{kPa})$ & 15 & 20 & 15 & 20 \\
\hline$\sigma_{\mathrm{r}(\mathrm{kPa})}$ & -21.2 & -23.0 & -16.5 & -14.9 \\
\hline$\sigma_{1}(\mathrm{kPa})$ & -21.2 & -23.0 & -17.5 & -15.7 \\
\hline Von Mises $(\mathrm{kPa})$ & 22.4 & 22.5 & 16.6 & 15.8 \\
\hline Deformation $(\mathrm{cm})$ & 4.8 & 4.4 & 4.1 & 3.4 \\
\hline
\end{tabular}

internal stresses were generated in the soft tissue near the ischial turberosity. For the contoured cushion, the load transferring form the bone is getting more and more smaller.

\section{DISCUSSION}

Finite element analysis was a powerful technique to consider the complex biological structures. However, the analytical results should be incorporated with experimental data to enhance the reliability. This study adopted Q.A. pressure measurement system to obtain the pressure and displacement. Comparing with experimental results validated the reliability of finite element models in this study.

When the cushion material became harder, i.e. increasing Young's modulus, the interface pressure increased and the deformation of the cushion decreased. According to the result, softer cushion materials had the ability to reduce the interface pressure. However, softer cushion might cause insufficient body support and result in the instability of sitting posture. Excessive muscle tension might be necessary for compensation and long-term fatigue would induce other muscular complications. As the consequence, the design of the chair for specialized purpose, such as $\mathrm{CP}$ and disabled patients, should afford enough body support incorporated with suitable cushion materials to prevent the formation of pressure sore.

\section{REFERENCES}

1. Dinsdake S M, "Decubitus ulclers: Role of pressure and friction in causation", Arch Phys Med Rehabil, Vol. 55, pp147-52, 1974.

2. Clark M O, Barvenel J C, Jordan M M and Nicol S M "Pressure sores", Nursing Times, Vol. 74, pp363-66, 1978.

3. Zachark D, "Wheelchair posture and pressure sores", Springfield (IL), Charles C. Thomas Publisher, 1984.

4. Crenshaw R P and Vistnes $L M$, "A decade of pressure sore research", J. Rehabil Res. Vol. 26(1), pp63-74, 1987.

5. Kosiak M, "Etilogy and pathology of ischemic ulclers", Arch Phys Med Rehabil, Vol. 40, pp62-9, 1959.

6. Rosen J M, Hentz V R and Perkash I, "The platic surgical management of pressure sores", Proceeding of the $39^{\text {th }}$ annual conference on engineering in medicine an biology, AEMB, pp97-100, 1980.

7. Chung K C "Tissue contour and interface pressure on wheel chair cushions, Ph.D. diss., University of Virginia, 1987.

8. Chow W W and Odell E I, "Deformation and stresses in soft body tissues of a sitting person", $J$. Biomech Eng, Vol.100, pp.79-87, 1978.

9. Fung Y C, "Biomechanics: Mechanical properties of living tissue", Springerverlag, 1981.

10. Todd B A, and Thacker J G, "Three-dimensional computer model of the human buttocks, in vivo.", $J$. of Rehabilitation Research and Development. Vol.2, pp.111-19, 1994. 